\title{
Global Abortion Policies Database: a Descriptive Analysis of Financial Coverage for Abortion Care
}

\author{
Antonella F. Lavelanet ${ }^{1}$ (D) $\cdot$ Esther Major ${ }^{2} \cdot$ Veloshnee Govender $^{1}$ (D) \\ Published online: 25 June 2020 \\ (C) World Health Organisation 2020
}

\begin{abstract}
Purpose of the Review The purpose of this review is to report on data available in the Global Abortion Policies Database (GAPD) as of February 2020. The GAPD is a repository of publicly available sources related to abortion for all countries.

Recent Findings Research indicates that where individuals must pay for abortion procedures, costs can often be unaffordable and catastrophic for households. Faced with financial barriers, individuals may be deterred from seeking healthcare or may resort to clandestine practices.

Summary There are limited countries with publicly available sources related to financial protection for abortion services. Even where legal access may be available on paper, several countries restrict actual access by limiting financial protection to specific types of individuals seeking abortion or certain legal categories of abortion, thus raising questions of equity and possible human rights violations. As countries advance towards universal health coverage (UHC), there is an urgent need to expand the GAPD to include additional data, building the evidence base on national health systems financing, and to consider the implications of financial protection with respect to access to abortion services.
\end{abstract}

Keywords Abortion · Laws · Policies · Financial protection · Universal health coverage · Insurance

\section{Introduction}

During the seventy-fourth session of the United Nations General Assembly, the political declaration on universal health coverage (UHC) recognized that UHC is "fundamental for achieving the Sustainable Development Goals [SDGs]

This article is part of the Topical Collection on Family Planning

Antonella F. Lavelanet

lavelaneta@who.int

Esther Major

esthermajor@icloud.com

Veloshnee Govender

govenderv@who.int

1 Department of Sexual and Reproductive Health and Research and UNDP-UNFPA-UNICEF-WHO-World Bank Special Programme of Research, Development and Research Training in Human Reproduction (HRP), World Health Organization, 20 Avenue Appia, CH-1211, Geneva 27, Switzerland

2 UNDP-UNFPA-UNICEF-WHO-World Bank Special Programme of Research, Development and Research Training in Human Reproduction (HRP) (Consultant), World Health Organization, 20 Avenue Appia, CH-1211, Geneva 27, Switzerland related not only to health and well-being, but also to eradicating poverty in all its forms and dimensions... [and] achieving gender equality and women's empowerment..." [1]. Under UHC, all individuals receive "needed promotive, preventive, curative, rehabilitative and palliative [quality] essential health services" without suffering financial hardship, ensuring that health remains a fundamental right $[1,2 \bullet, 3]$. As part of its thirteenth General Programme of Work, the World Health Organization (WHO) supports countries in health system strengthening to attain and sustain UHC [4].

Progress towards UHC requires access to a full range of health services, which are of good quality, and where the emphasis is on all people getting the services they need. In addition, individuals need to be protected from the financial risk associated with seeking healthcare. Financial risk is primarily associated with out-of-pocket payments (OOPs), which include user fees; out-of-pocket payments for medicines; diagnostics; additional procedure charges; transportation; and other informal charges incurred at the time of service use [5••]. Where healthcare costs are a barrier, individuals may be deterred from seeking healthcare [6].

The impacts of healthcare costs and specifically OOPs may be magnified when considering services that are stigmatized or legally restricted, such as abortion. Costs associated with 
induced abortion are often unaffordable and can be catastrophic for individuals and households [7]. Individuals may resort to coping strategies, including the use of savings or borrowing money at high interest rates [7]. Economic deterioration, however, is not restricted to induced abortion. Costs for management of spontaneous abortion or post-abortion complications can also lead to loss of assets, incurred debt, loss of productivity, costs to the health system, and consequences for families [7, 8]. In addition to facility costs, individuals may experience significant financial losses even prior to presenting for management [8] or face additional user fees applied at the point of care [9]. These financial impacts are magnified in populations that are socially or economically disadvantaged, including those who are poor [7, 8] and women of colour [10].

Publicly funded health systems do not always include abortion services in their health benefit packages, which is necessary for ensuring that services are subsidized (fully or partially) to alleviate costs to users $[11,12]$. These healthcare costs create an obstacle for those without the means to pay, resulting in some women resorting to clandestine practices at great per-

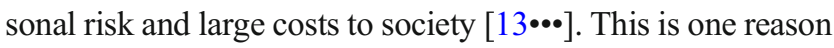
that the World Health Organization (WHO) Safe abortion: technical and policy guidance for health systems states that women should be able to access legal abortion regardless of their ability to pay.

In this paper, our main objective is to use data extracted from the Global Abortion Policies Database, to report on the number of countries that have publicly available documents related to financial protection, including particular types of insurance (public, private and/or a combination of the two), or other measures to offset end user costs specific to abortion. We further seek to describe how and if these policies attempt to ensure whether individuals can access all legal categories of abortion regardless of their ability to pay and highlight the limitations of relying on publicly available information.

\section{Methods}

The Global Abortion Policies Database (GAPD) is a tool that presents information on abortion laws and policies, including information related to legal categories, access requirements, and service provision. The GAPD includes information for 198 member states. We use data available in the GAPD as of February 2020; information in the database is limited by accessibility of source documentation and the ability to translate source documents. The methods used for collecting, classifying, and coding data in the GAPD have been previously described [14]. In brief, a data extraction questionnaire was used to populate the GAPD, with coding based on the explicit text of the law, policy, or guideline. We included only countries where access to abortion is lawful on the woman's request with no requirement for justification and/or for one or more legal ground(s) [15].

Universal health coverage, including service, population, and financial coverage, varies widely in countries. Thus, for this paper, we analysed all policies (including laws and standards and guidelines) available in the GAPD that are related to financial coverage available for abortion, including insurance (public, private, and/or a combination of the two), or those policies that describe other measures to offset user costs. We do not consider additional regulatory requirements, as these have also been reviewed elsewhere [16].

\section{Results}

We present data for 41 countries, as the policies for these countries are available in the GAPD; where additional information is available at the sub-national level, this has been described (Table 1).

\section{Coverage for All Individuals for All Legal Categories}

In 17 countries, policies exist describing coverage for all individuals seeking an abortion procedure regardless of the indication. In Northern Ireland, where individuals must travel to access services, travel and accommodation are also covered. In Switzerland, coverage is the same across all cantons. In Canada, 4 provinces (Alberta, British Columbia, Manitoba, and New Brunswick) provide coverage for all individuals seeking abortion services.

\section{Coverage for All Individuals for Selected Legal Categories}

In 12 countries, coverage for abortion is provided for all individuals, but only for selected legal categories. For example, in Hungary, individuals seeking an abortion due to a health condition or fetal anomaly will be covered by social insurance. For all other individuals seeking an abortion in Hungary, the fees charged for the procedure cannot exceed the amount normally financed under social insurance. In the Republic of Moldova, where access to abortion is legally permitted for several legal categories, only abortions performed for fetal indications are covered.

In 9 of these countries (Austria, Bosnia and Herzegovina Republika Srpska, Bulgaria, China, Lithuania, Montenegro, North Macedonia, Slovakia, and Vietnam), although abortion is legally permitted on request, coverage is restricted to medical indications. Five of these countries (Bosnia and Herzegovina Republika Srpska, Lithuania, Montenegro, North Macedonia, and Slovakia) explicitly specify selected legal categories of abortion and exclude coverage for individuals seeking abortion on request. 
In Montenegro, abortion is also covered in cases of threat to life/health threat, fetal impairment, conception that occurred as the result of a criminal offence, or when the pregnancy or childbirth would lead to personal or family difficulties. In Germany and Bulgaria, abortion is covered for those seeking abortion for rape.

\section{Coverage for Certain Individuals for All Legal Categories}

In 10 countries, there is coverage for all legal categories, but only for certain individuals. For example, in Israel, procedures performed on adolescents less than 18 years of age accessing abortion for medical or non-medical reasons will be covered. In Germany, all legal categories are covered but only for those who are economically disadvantaged and cannot be reasonably expected to raise the funds to cover abortion services. Montenegro covers the cost of abortion on request for all poor women.

Abortion-related care is covered specifically for residents of Mexico City, while a sliding scale fee, based on income, is applied for residents of other Mexican states. In Uruguay, individuals are covered for all legal categories for individuals who have lived in the country for more than a year. In the Netherlands, unlawful persons resident in the country are not insured for abortion-related services. In New Zealand, only those eligible for funded healthcare are covered, excluding seasonal migrant women, non-residents, and international students, and similarly, in Ireland, the policy covers all who are normally resident in the country. In Canada, 2 territories and 6 provinces (North West Territories, Newfoundland and Labrador, Nova Scotia, Ontario, Prince Edward Island, Sasketchavan, Quebec, and Yukon) specify in their local governance policies that coverage is restricted to holders of a valid health card. ${ }^{1}$ In Victoria, Australia, coverage is provided for all categories, but may vary depending on who qualifies for assistance; whether the service is received in a public, private, or community setting; and the type of procedure being performed.

\section{Coverage for Certain Individuals for Selected Legal Categories}

Four countries provide coverage for specific individuals only for certain grounds. For example, in Israel, abortion procedures are covered for all women up to the age of 33 if the pregnancy was the result of rape, there is a fetal anomaly, or the pregnancy poses a risk to the woman's life, physical or mental health. In the Czech Republic, citizens are covered for medical indications, but not for abortions accessed on request; non-citizens and those temporarily staying in the country have

$\overline{{ }^{1} \text { Information for }}$ one province, Nunavut, could not be located. no financial coverage. In Estonia, coverage is available for all women, but coverage is not provided in entirety, rather, abortion is subsidized according to an individual's ability to pay, up to $70 \%$ for the procedure if done on request with anaesthesia and up to $50 \%$ for medical abortions.

In the USA, individuals who qualify for Medicaid based on economic eligibility are eligible for coverage for abortion procedures secondary to life or health threat or where the pregnancy is the result of rape.

\section{Coverage for Complications}

Seven countries explicitly provide coverage for complications resulting from pregnancy or from abortion. In Colombia, the constitutional court has specifically stated that it is unlawful to deny access based on the type of insurance one has, but there is no expressed statement of coverage for all women.

\section{Discussion}

The objectives of UHC include equitable access to quality care, delivered in a way that does not create financial risk for individuals. While all possible interventions cannot be included in a single country's coverage scheme, coverage for services that address the most significant causes of morbidity and mortality should be included [17]. With 25 million unsafe abortions taking place each year [18], resulting in approximately 23,000 abortion-related deaths [19], the need for safe abortion that is affordable is evident. It is difficult for individuals, however, to obtain services where there is no financial protection and the results of this analysis further demonstrate that only 17 countries have publicly available documents describing financial protection related to abortion for all individuals for all legal categories.

Financing of health systems can occur in a variety of ways. Free health care (FHC) policies to eliminate formal fees at the point of service are one way to address a component of healthcare costs. These policies can include all services for specific individuals, or specific services for all individuals, in an attempt to protect the medically or economically vulnerable. Here, 12 countries provide financial protection related to abortion for all individuals for selected legal categories, such as medical or fetal indications. No information is provided in the source documents as to why these particular indications are covered, but such selective coverage may be related to the perceived financial risks associated with the continuation of pregnancies complicated by medical risks. Countries utilizing FHC must allocate additional funding at the service provider level to compensate for the loss of user fees and establish incentives for provision and accountability [6]. However, countries may be reluctant to allocate additional funding and 


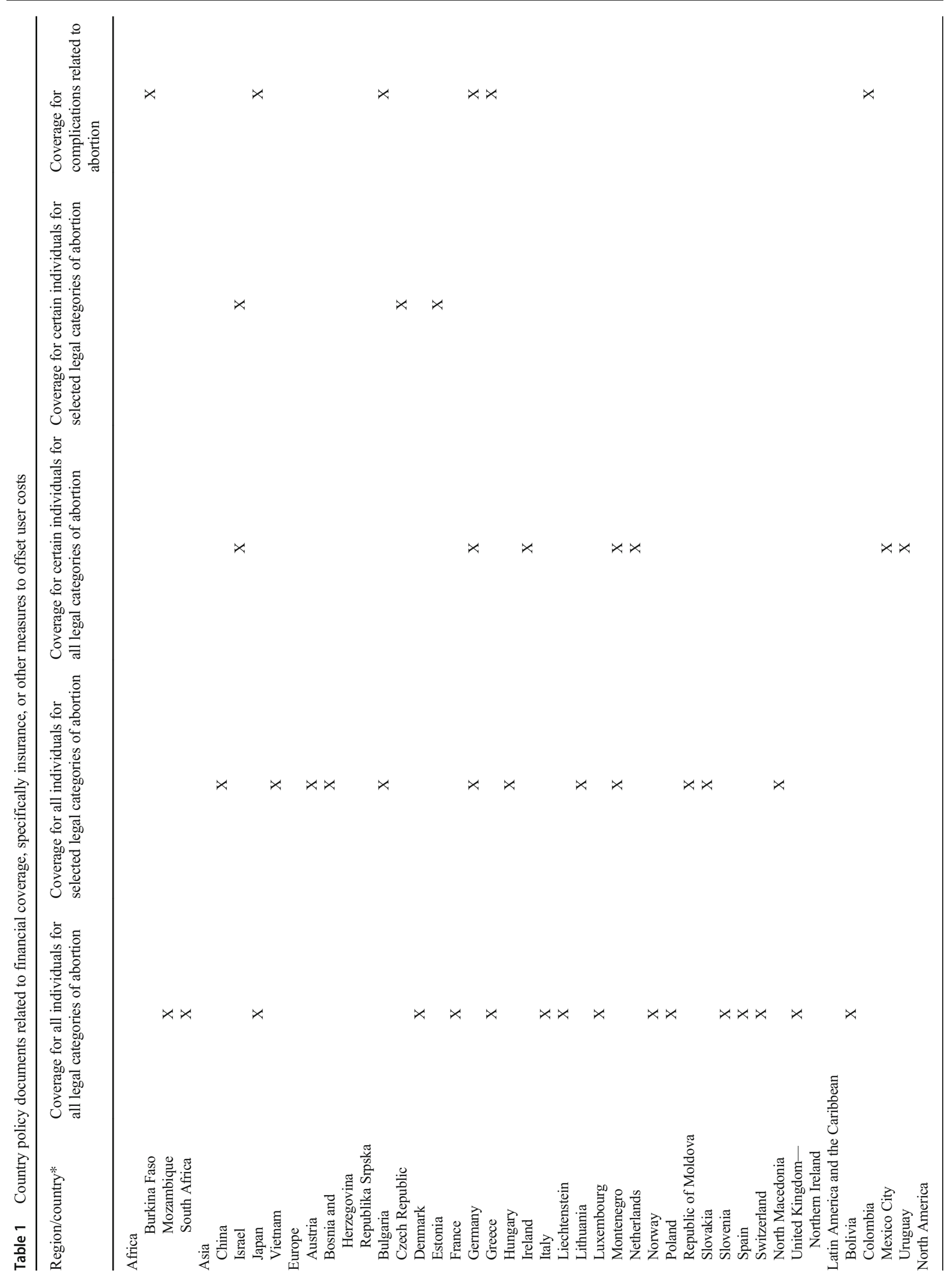




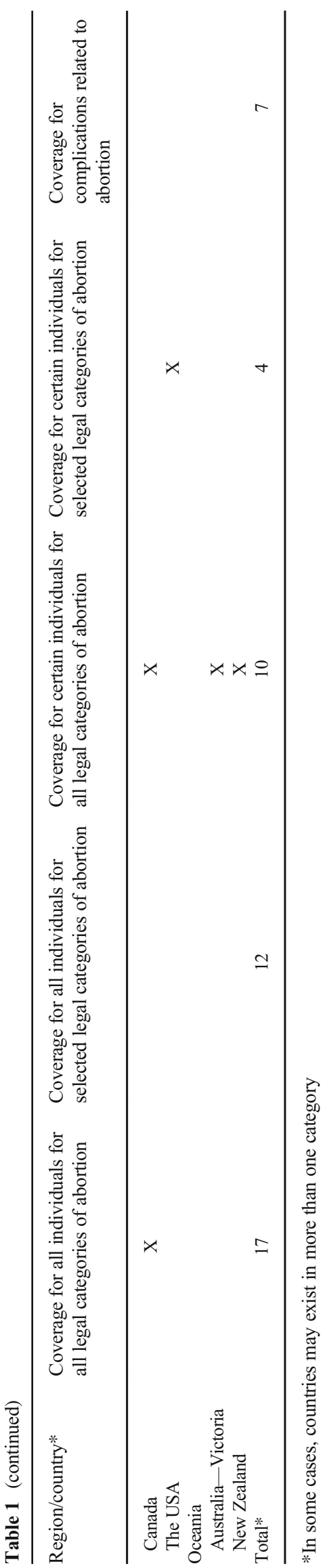

incentivize service provision; as like many other sexual and reproductive health issues, abortion is highly stigmatized.

Selective financing raises questions of equity and fairness. Some countries explicitly exclude financial protection for abortions performed on request; thus, questions are raised as to whether the lack of coverage is punitive in nature. Where some groups of women are unable to access to an abortion on request due to the decision by some states to not fund such procedures, it reinforces pre-existing inequalities; only women with economic resources can access abortion on request, while women and adolescents who are poor are ultimately denied that legal category of abortion. Yet, some countries have financing policies focused on selected populations, including adolescents, with a potential recognition of their specific challenges to accessing services as well as an acknowledgement that protection of adolescent health is an investment in the community at large. Financial protection for selected groups of individuals could also suggest a hierarchy in the acceptability of the type of women accessing services.

However, to progress to UHC, the health system must be funded predominantly through domestic public funding that combines taxes and other prepayment mechanisms, yielding a more sustainable, efficient, and equitable base to ensure social protections related to health $\left[5 \bullet^{\circ}\right]$. Doing so also means moving away from funding heath care and basing access on contributions through voluntary prepayment and employmentbased mechanisms. Resultant schemes may include national health insurance or social health insurance models.

While, the GAPD provides some insight into particular types of financial coverage, insurance, or other measures to offset end user costs, there are pitfalls to relying on publicly available information only. Available documents do not describe, for example, how such financing schemes are covered; are these schemes covered by public or private actors? As most policy documents speak to abortion generally, little information is provided as to what services are actually covered (e.g. method of evacuation (medical and/or surgical), anaesthesia or other ancillary services). Very little information exists as to financial protections related to additional costs, including for travel, or medicines related to medical abortion, such as those obtained at local pharmacies. Finally, the information in the database is also limited by the inability to translate all source documents, in the absence of official translation.

Where individuals have to pay for abortion procedures, costs can be as high as twice the typical amount paid for annual out-of-pocket health care expenses [20]. In the absence of financial protection for abortion services, or where user fees exist, there is an increased risk that individuals will forgo services or resort to substandard care. Individuals may also attempt to self-induce where costs are a barrier [20] or feel compelled to continue with an unwanted and/or dangerous pregnancy. 
Furthermore, in most countries, abortion is regulated through the criminal law, unlike most other healthcare services, potentially contributing to the reluctance of some states to finance abortion services. This seems counter to human rights standards requiring countries to be responsive to the needs of their populations [21]. This is despite the overwhelming cost of unsafe abortion and inefficiencies associated with the use of hospital resources. Out-of-pocket payments, for example, for individuals and households in sub-Saharan Africa related to post-abortion complications, have been previously estimated to be US\$200 million each year for the treatment of post-abortion complication, with US\$930 million estimated to be the annual expenditure for morbidities and mortality related to unsafe abortion [13•]. This may be why 7 of the 41 countries have specific coverage for post-abortion complications.

There are serious implications for women and girls and potential for violations of their fundamental human rights in contexts where there is only partial or no funding of abortion services. This is perhaps why the United Nations (UN) expert committees, responsible for monitoring compliance with international human rights treaties, are increasingly raising concerns about the lack of coverage for abortion services for all women in all legally available categories of abortion. For example, the UN Committee for the Elimination of all forms of Discrimination against Women (CEDAW) has called on countries to "ensure universal coverage by public health insurance" for "all costs relating to legal abortion, including abortion on request" [22]. Such recommendations recognize the need for "unimpeded and effective access to legal abortion and post-abortion services to all women" [22], a position which has been supported by several UN Committees [23-26].

Finally, while there is no single right way to achieve UHC, countries must also look for additional ways to improve both healthcare efficiencies and equitable access [5••]. WHO has provided guidance on task sharing [27] and techniques such as manual vacuum aspiration and medical abortion that require limited infrastructure [13•]. The implementation of such guidance can assist countries to get the most out of existing technologies and health services, resulting in greater efforts towards obtaining UHC $[5 \bullet \bullet$.

\section{Conclusion}

The results of this study indicate that there are limited source documents publicly available related to insurance coverage or other funding mechanisms for abortion services within the GAPD. Even with limited data, what is available on the GAPD shows that some countries have taken steps to ensure that where there is legal access to abortion, that financial protection does exist for individuals needing such services.
The World Health Organization (WHO) Safe abortion: technical and policy guidance for health systems states that women should be able to access legal abortion regardless of their ability to pay. The results of this study indicate that for many women around the world, even where abortion is permitted on request, actual access to safe abortion services may remain out of reach for those who cannot pay, particularly those who are poor, young or have uncertain legal status. Inclusion of abortion services in a country's health benefit package is one important way to ensure that abortion services will be at least partially if not fully subsidized by the state. Health services that are preventative, promotive and curative are meant to be included in UHC; yet, even where financial protections exist for abortion for all individuals, questions of equity remain, with very few countries financing abortion on request. Further research and expansion of the GAPD are needed to investigate and build the evidence related to ways in which countries create and implement policies related to financing, including how and whether such policies protect those that are most vulnerable.

Availability of Data and Material The data generated and/or analysed during the current study are available in the publicly available Global Abortion Policies Database (http://abortion-policies.srhr.org).

Authors' Contributions AFL and VG conceptualized this manuscript. AFL completed the first draft, AFL and EM collected and analysed the data, and all authors contributed to subsequent revisions. All authors read and approved the final manuscript.

Funding Information This work was supported by the UNDP-UNFPAUNICEF-WHO-World Bank Special Programme of Research, Development and Research Training in Human Reproduction (HRP), a cosponsored programme executed by the World Health Organization (WHO). Collection of the data, analysis, and composition of this manuscript was performed by WHO staff members and a WHO consultant. AFL's, VG's, and EM's salary is supported by the HRP Trust Fund.

\section{Compliance with Ethical Standards}

Conflict of Interest The authors declare that there is no conflict of interest regarding the publication of this manuscript. The views expressed in this article are those of the authors and do not necessarily represent the views of, and should not be attributed to, the World Health Organization.

Human and Animal Rights and Informed Consent This article does not contain any studies with human or animal subjects performed by any of the authors.

Code Availability Not applicable.

Ethics Approval Not applicable.

Consent to Participate Not applicable.

Consent for Publication Not applicable. 
Open Access This article is licensed under a Creative Commons Attribution 4.0 International License, which permits use, sharing, adaptation, distribution and reproduction in any medium or format, as long as you give appropriate credit to the original author(s) and the source, provide a link to the Creative Commons licence, and indicate if changes were made. The images or other third party material in this article are included in the article's Creative Commons licence, unless indicated otherwise in a credit line to the material. If material is not included in the article's Creative Commons licence and your intended use is not permitted by statutory regulation or exceeds the permitted use, you will need to obtain permission directly from the copyright holder. To view a copy of this licence, visit http://creativecommons.org/licenses/by/4.0/.

\section{References}

Papers of particular interest, published recently, have been highlighted as:

- Of importance

•- Of major importance

1. UN General Assembly. Political declaration of the high-level meeting on universal health coverage, 10 October 2019, A/RES/74/2. https://undocsorg/en/A/RES/74/2. Accessed 27 March 2020.

2. The World Health Report. Research for universal health coverage. Geneva: World Health Organization; 2013. The report focuses on the importance of research in advancing progress towards universal health coverage.

3. UN General Assembly. Entry into force of the constitution of the World Health Organization, 17 November 1947, A/RES/131. https://wwwrefworldorg/docid/3b00f09554html Accessed 27 Feb 2020.

4. Thirteenth general programme of work 2019-2023. Geneva: World Health Organization; 2019.

5.• The World Health Report. Health systems financing: the path to universal coverage. Geneva: World Health Organization; 2010. This report identifies what countries can do to modify their financing systems and move towards universal health coverage.

6. Mathauer I, Mathivet B, Kutzin J. Free health care policies: opportunities and risks for moving towards UHC. Geneva: World Health Organization; 2017.

7. Ilboudo P, Greco G, Sundby J, Torsvik G. Costs and consequences of abortions to women and their households: a cross-sectional study in Ouagadougou, Burkina Faso. Health Policy Plan. 2015;30(4): 500-7. https://doi.org/10.1093/heapol/czu025.

8. Sundaram A, Vlassoff M, Mugisha F, Bankole A, Singh S, Amanya $\mathrm{L}$, et al. Documenting the individual- and household-level cost of unsafe abortion in Uganda. IPSRH. 2013;39(4):174-84.

9. Duggal R. The political economy of abortion in India: cost and expenditure patterns. Reprod Health Matters. 2004;12(24 Suppl): 130-7.

10. Boonstra $\mathrm{H}$. Abortion in the lives of women struggling financially: why insurance coverage matters. Guttmacher Policy Review: 2016; 19. https://www.guttmacher.org/gpr/2016/07/abortion-liveswomen-struggling-financially-why-insurance-coverage-matters. Accessed 27 March 2020.
11. Prioritizing essential packages of health services in six countries in Sub-Saharan Africa. 2019. https://www.who.int/pmnch/media/ news/2019/Full-report.pdf. Accessed 27 March 2020.

12. HERA Right to Health \& Development. Universal health coverage for sexual and reproductive health in the Asia-Pacific region. Belgium. 2018. https://asiapacific.unfpa.org/sites/default/files/pubpdf/UNFPA SRH hera 171023 web optimized.pdf. Accessed 27 March 2020.

13. $\cdots$ Safe abortion: technical and policy guidance for health systems, second edition. Geneva: World Health Organization; 2012. This guideline provides evidence-based guidance on clinical care, as well as information on how to establish and strengthen services, and outlines a human-rights-based approach to laws and policies on safe, comprehensive abortion care.

14. Johnson BR, Lavelanet AF, Schlitt S. Global abortion policies database: a new approach to strengthening knowledge on laws, policies, and human rights standards. BMC Int Health Hum Rights. 2018;18:35. https://doi.org/10.1186/s12914-018-0174-2.

15. Lavelanet AF, Schlitt S, Johnson BR, Ganatra B. Global abortion policies database: a descriptive analysis of the legal categories of lawful abortion. BMC Int Health Hum Rights. 2018;18:35. https:// doi.org/10.1186/s12914-018-0183-1.

16. Lavelanet AF, Johnson BR, Ganatra B. Global abortion policies database: a descriptive analysis of the regulatory and policy environment related to abortion. Best Pract Res Clin Obstet Gynaecol. 2019;62:25-35. https://doi.org/10.1016/j.bpobgyn.2019.06.002.

17. World Health Organization. Universal health coverage - key facts. 2019. https://www.who.int/en/news-room/fact-sheets/detail/ universal-health-coverage-(uhc). Accessed 27 March 2020.

18. Ganatra B, Gerdts C, Rossier C, Johnson BR Jr, Tunçalp Ö, Assifi A, et al. Global, regional, and subregional classification of abortions by safety, 2010-14: estimates from a Bayesian hierarchical model. Lancet. 2017;390(10110):2372-81. https://doi.org/10.1016/S01406736(17)31794-4.

19. Say L, Chou D, Gemmill AT, OMoller AB, et al. Global causes of maternal death: a WHO systematic analysis. Lancet Glob Health. 2014;2:e323-33. https://doi.org/10.1016/S2214-109X(14)70227$\mathrm{X}$.

20. Grossman D, Grindlay K, Burns B. Public funding for abortion where broadly legal. Contraception. 2016;94(5):453-60.

21. Erdman JN, Cook RJ. Decriminalization of abortion - a human rights imperative. Best Pract Res Clin Obstet Gynaecol. 2020;62: 11-24. https://doi.org/10.1016/j.bpobgyn.2019.05.004.

22. UN Committee for the Elimination of all forms of Discrimination against Women, concluding observations for Slovakia, CEDAW/C/ SVK/CO/5-6 (25 November 2015), para 30 and 31.

23. UN Committee on the Rights of the Child, concluding observations for Slovakia, CRC/C/SVK/CO/3-5 (20 July 2016), para 39 and 40.

24. UN Human Rights Committee. Concluding Observations for Ghana, CCPR/C/GHA/CO/1 (9 August 2016), para 23 and 24.

25. UN Committee for the Elimination of all forms of Discrimination against Women, concluding observations for Serbia, CEDAW/C/ $\mathrm{SRB} / \mathrm{CO} / 2-3$ (30 July 2013), para 32 and 33.

26. UN Human Rights Committee. Concluding observations for $\mathrm{St}$ Vincent and the Grenadines, CCPR/C/VCT/CO/2/Add.1 (9 May 2019), para 20 and 21.

27. Health worker roles in providing safe abortion care and postabortion contraception. Geneva: World Health Organization; 2015.

Publisher's Note Springer Nature remains neutral with regard to jurisdictional claims in published maps and institutional affiliations. 